there was ample room for the head to enter the pelvis, it was thought that it was prevented from doing so by the presence of a tumour such as a fibroid; but clinical examination ruled out this possibility.

The subsequent findings at operation of a full-time orarian pregnancy lend exceptional interest to this series of skiagrams. The radiography of the unborn baby is a very recent advance in radiology, and these skiagrams are, in all probability, the first on record of a case of this nature.

As the $x$-ray appearance of a normal foetus in utero is unfamiliar to many, a skiagram of a normal full-time vertex presentation is also shown.

\section{DISAPPEARING DISEASES.*}

\section{BY}

\section{E. S. FLEMMING, M.R.C.S., L.R.C.P., BRADFORDTON-AVON.}

When Mr. Levis did me the honour to ask me to read a paper I thought that as I had just completed forty years of life as a qualified medical man I ought to have something to talk about; but I found it by no means easy to find a subject suitable for a society such as this until one day, while perusing the last report of the Chief Medical Officer to the Ministry of Health, I read the figures relating to the death rate of England and Wales, and noticed that it had dropped, during the past fifty ycars, from 21.4 to 12.2 per 1,000 living, and the question suggested itself. At what points in the wide battle front of disease had death been repulsed, and for which of these successful fights could we claim credit?

My intention is to give my own impressions as to the decline in frequency of the incidence and the severity of attack of certain diseases and morbid conditions, but before doing so I give you some figures published by the Ministry of Health, as they are accurate records of actual facts, and while they deal only with death rates they may be taken as an index of the incidence and the severity of the diseases referred to.

Table showing the Decline in the Death Rates (per 1,000 population) from Certain Infectious Diseases in the Period 1871 to 1924.

\begin{tabular}{|c|c|c|c|c|c|}
\hline & & & 1871-1880. & 1924. & Decrease. \\
\hline Death rate $\ldots$ & ... & ... & 21.40 & 12.20 & $\begin{array}{c}\text { Per cent. } \\
43.0\end{array}$ \\
\hline Infant mortality (1891) & ... & $\ldots$ & 150.00 & 75.00 & 50.0 \\
\hline Diphtheria (1891-1900) & ... & $\ldots$ & 0.26 & 0.06 & 77.0 \\
\hline Enteric fever & $\ldots$ & $\ldots$ & 0.32 & 0.01 & $93 \hat{.9}$ \\
\hline Scarlet fever & $\cdots$ & ... & 0.72 & 0.02 & 97.3 \\
\hline Small-pox $\ldots \quad \ldots$ & $\ldots$ & $\ldots$ & 0.24 & 0.00 & 100.0 \\
\hline Tuberculosis (respirator & & $\ldots$ & 2.13 & 0.84 & 60.0 \\
\hline
\end{tabular}

This table is a striking record of the disappearing in varying degree of a group of widespread and serious maladies. Except that $I$ have never seen, in private practice, a case of small-pox, the figures here shown are, in their general import, in accord with my own experience.

In the defeat of each of these diseases medicine, curative and preventive, may justly claim to have had a share either directly or indirectly, but we must be careful as to the extent of our claim, since the general improvement in the conditions of the life of the people must have had a large influence in the betterment of their health. Except, perhaps, in the case of rabies it is doubtful whether wethe medical profession and those acting on our advicecan demand credit for the immediate, intentional, direct, and entire control of any one disease. We pride ourselves and our health administration on the reduction in the death rate of phthisis; but $I$ would draw your attention to the accompanying chart (drawn up from figures supplied

\footnotetext{
* A paper read before the Bath Clinical. Society, January 8th, 1926.
}

by the Ministry of Health) for the years 1847 to 1924, which, it must be remembered, records not the incidence of the disease but the deaths. Note the long steady decline. What influence had the Local Government Act of 1875? During the thirty years preceding it the rate per million had declined by 1,000, during the thirty years succeeding it the rate declined by 1,100 . Looking at the chart, it does not appear that any decrease in the death rate followed the discovery of the infecting organism, or that any influence has been exerted by sanatorium treatment and the general campaign against tuberculosis which have been so actively carried on during the last twenty years. The only remarkable point is that the rate rushed up in a startling manner during the years of the war, to fall immediately the war ceased.

It may be urged that without all this activity there might have been a stop in the decline; on the other hand, it may be that the decline is due to a naturally produced immunity of the community, a growing power of resistance to the disease, or the infecting organism may by some natural process be undergoing a change to a less virulent type.

The infectious diseases already noticed naturally occurred to mo as the most notable of disappearing diseases, but there are others that present themselves to all of us, in varying degree according to our personal experience. Such, for instance, is gout; how rarely now, compared with forty years ago, does one see a classical case of acute gout. In Bath, the Mecca of the footsore arthritic pilgrim, those who are the high priests of the hydrotherapeutic prophet may have a false impression of the prevalence of gout, though it may be that even they have noticed a falling off in the numbers attending the steany shrine. Is this decline due solely to dietetic reasons, chiefly to the greatly decreased consumption of port wine and beer, and so only one of the contingent results in the decrease in alcoholism? Surely one of the most outstanding facts in a survey of the last few decades of-medical practice is this decrease in alcoholism and all its associated morbid conditions.

How seldom now, compared with thirty years ago, does one have to treat a serious case of acute rheumatism, socalled rheumatic fever; if this is not merely a personal experience, what is the explanation of the diminution in the number of these cases?

In a list of disappearing diseases in ordinary surgery or consulting-room practice $\mathbf{I}$ should be inclined to put first anaemia; it seems not long since one was always attending not one but several cases of chlorosis, chiefly, though by no means only, among girls of the servant or working class; now how comparatively rare these patients are. Better conditions of life, of home and workshop, the stopping of child labour, shorter hours of work, better food, more sunlight and air, more rational dress, more outdoor recreation, and last, but by no means least, better teethall of these things have, I suppose, been instrumental in this change; and with the decrease in this form of anaemia there must have been a decrease in many conditions attendant on it, such as gastric ulcer, headache, heart failure, and phthisis. Also, I assume, due to the healthier and happier life is the decrease in the number of cases of hysteria, which not long ago were so frequent among the young women whose physical and mental energies were unnaturally restricted. This is the more notable when we realize the apparent increase in so many other morbid nervous and psychical conditions.

Another disease that is much less prevalent is rickets; this is due no doubt to better conditions of life. Here again it may appear to those having charge of the clinics in an orthopaedic centre such as Bath has become that this statement is not justified, but $I$ would like to know the opinion of those in general practice who see these cases in the first instance.

There are many conditions which are much less frequently met with now, which can, perhaps, hardly be described as dying diseases, because they are merely the result of the more effective treatment in an early stage of some disease or deformed condition. Such, for instance, are strangulated hernia, daily becoming less frequent, for the obvious reason that hernias are cured before they become strangulated; peritonitis, which thirty years ago was probably in 


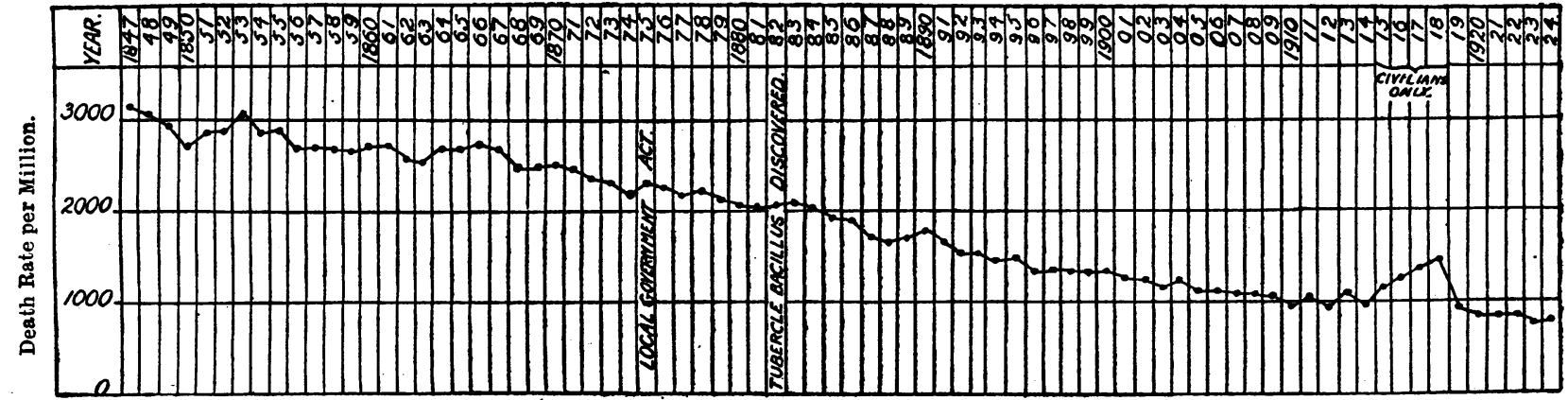

nine cases out of ten neglected appendicitis; persistent headaches, due to errors of refraction.

Lupus, which is now treated early and successfully, and gastric ulcer, which is now actually cured in hospital by the physician or, failing him, by the surgeon, may be only apparently less frequent, for they, like many other conditions, have possibly, on account of their long duration, given rise to a false impression of their prevalence. For example, one patient with gastric ulcer would require many attendances over a long period of time and leave on the mind of the medical attendant the impression of many cases, with the consequence that when such a case is cured early in its life it may incline one to think that gastrio ulcers are less frequent than they used to be.

Again, there are some conditions that may appear to be less frequent because it is no longer fashionable to look for them or to talk about them-such, for example, as movable kidney and displaced uterus, both at one time the delight of the seeker after sympathy and for the doctor dividendearning ailments. So, no doubt, in due time " blood pressure" will become a less fashionable and less prevalent complaint.

Although it is not a disease, I almost think that we might add to the list of disappearing diseases senility; if it is not disappearing there is much evidence that its onset is postponed by several years.

There is little profit in merely registering the fact of the decline of a disease unless at the same time we can form some idea of the causes of that decline; in the case of the zymotic diseases this is not so difficult, though it is by no means easy to assess the value of the part played by the different agents. It is at any rate obvious that each section of the medical profession-the laboratory worker, the clinician, and the public health administrator-has had an important share in the campaign. Medicine in the fruition of its work has been helped by the State; the State has been dependent on the medical profession, but the brunt of the battle has fallen on the medical man, who has had for long weary years to educate and to persuade an unwilling, an unbelieving, and a not always grateful, public that if only it will listen and help it may be relieved of many of its ills.

With the good old times, whose passing many lament, have passed diseases and conditions of life that none can want back; with improving medical knowledge and service and conditions of life we may look with hope to the disappearance of still more diseases.

Are we ever justified in concluding that any diseases naturally get less virulent and then disappear? What is the reason of the undoubted milder type of some of the infectious diseases-such, for example, as small-pox? Is it due to vaccination and an inherited immunity? If so, why in the recent epidemic in Gloucester was there no difference in the character of the disease in the unvaccinated, whether they were the children of vaccinated parents, or of one or two generations of unvaccinated parents?

Why is it that scarlet fever has become so much less serious? There can be no question of artificial immunity, and one can hardly think that the mere isolation of some of the cases can account for this alteration. Although, judging by the analogy of diphtheria, it may be argued that isolation may have some influence. in affecting virulence, the earlier cases in an epidemic of diphtheria are generally of a very mild type; as the epidemic increases the type becomes more virulent; if, however, the earliest cases are effectively treated and isolated there is not the same increase in virulence.

Is not the disappearance of an infective disease due to altered conditions which render its continuance difficult? Given the old conditions, would it not reappear?

Are we to look forward to a time when, having been freed from all diseases, we shall, like the antivaccinators, lulled into a false sense of security, forget the forces that drove them out, and, relapsing into the old conditions-an unprepared, a non-immunized, and non-resisting communitybo attacked with devastating effect?

\section{Attemuranda:}

\section{MEDICAL, SURGICAL, OBSTETRICAL.}

\section{THE PREDIVERTICULAR STATE AND DIVERTICULOSIS.}

THE recent interesting article by E. I. Spriggs and $O$. A. Marxer (January 23rd, p. 130) throws a considerable light on the etiology of diverticulitis of the sigmoid colon. Thi fully developed condition is well recognized by surgeons, but no satisfactory explanation of the train of events which leads up to the formation of the saccules has been given previous to the report of Marxer in 1923. A recent case in which I have had the opportunity of seeing the colon at operation confirms and amplifies the observations they record in the article mentioned above.

The patient, a man aged 43, had suffered from the passing of loose motions for three or four years; in the latter part of this period he occasionally passed a little blood. Latterly he had a pertle vague discomfort in the left iliac fossa, but continued to work till brought to hospital, alarmed by the blood in his motions. He was sallow and anaemic. On abdominal examination a somewhat tender spastic colon could be felt in the left iliac fossa; by the rectum the mucosa felt velvety and inflamed. A barium enema of $70 \mathrm{oz}$. was given without pain, and the picture had all the characteristics mentioned by Spriggs and Marxer: passing out of the ampulla of the rectum there was a length of colon going for some four inches for some four inches upwards and to the left. This segment was narrowed and its edges presented that peculiar spiky condition so well shown in their illustrations. The radiograph of this length of bowel conveyed to the eye the sense of a rigid

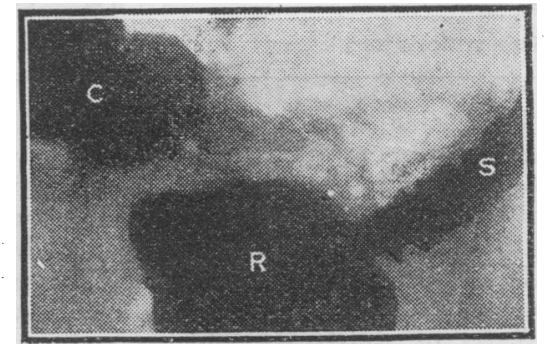

c, Caecum. R, Recium. s, Sigmoid. walled tube with weak areas in it and contrasted strongly with the distensile colon, into which
bowel.

Sig. Dast the bowe past the rectum owing to pain and inability to distend the bowe properiy, while the view was constantly spoilt by blood-stained mucus coming from the bowel above. Laparotomy was performed spinal anaesthesia. The sigmoid colon, on examination, showed no gross changes, no saccules, no excessive deposit of fat, no narrowing. Its walls were rather thicker than normal, however, and the areas between the longitudinal bands showed 